\title{
Study on two-stage ignition of two interactive droplets in flame spread over $\boldsymbol{n}$-decane droplets in microgravity
}

\author{
Yuto Chikami*1, Kodai Matsumoto ${ }^{1}$, Takehiko Seo ${ }^{1}$, and Masato Mikami ${ }^{1}$ \\ ${ }^{1}$ Department of Mechanical Engineering, Yamaguchi University, Ube, Japan \\ ${ }^{*}$ Corresponding author email : a023vdu@yamaguchi-u.ac.jp
}

\begin{abstract}
Microgravity experiments on flame spread over droplet arrays were conducted using $n$ decane as the fuel at 0.3 and $0.4 \mathrm{MPa}$. This study focused on the cool-flame appearance and two-stage ignition during flame spread over fuel droplets. Previous studies have reported that when a single droplet is inserted into a high-temperature, high-pressure furnace, two-stage ignition occurs in which a hot flame appears after a cool flame. In addition, we have reported that the cool flame appears in the flame spread over fuel droplets, but two-stage ignition was not observed. Therefore, this study further investigated whether two-stage ignition could occur in flame spread over some combinations of $n$-decane droplets in microgravity. Droplets were tethered at intersections of 14-micron SiC fibers. The flame spread was observed by an infrared camera, and the appearance of a cool flame was identified using the Thin Filament Pyrometry (TFP) method for the SiC fibers tethering the droplets. The results show that twostage ignition occurs around two interactive droplets during flame spread at $0.4 \mathrm{MPa}$. After a cool flame appears, a rapid temperature rise occurs between the two droplets, leading to the appearance of a hot flame.
\end{abstract}

\section{Keywords}

Flame spread, Droplet array, Two-stage ignition, Cool flame, Microgravity

\section{Introduction}

Droplet combustion has been studied to elucidate the mechanism of spray combustion, which is used in many combustors. For example, flame spread over fuel droplets in microgravity has been studied using simplified droplet systems, such as droplet arrays, droplet-cloud elements, and randomly distributed droplet clouds.

The premixed combustion of hydrocarbon fuels with more than three carbons shows a low temperature burning phenomena called a "cool flame" at 580-750 K [1-2]. Tanabe et al. [3] experimentally researched the auto-ignition process of single droplets at different ambient temperatures and pressures in air and showed that the cool flame appears during auto-ignition even in droplet combustion and that there are four types of droplet auto-ignition processes: cool-flame ignition, only the cool flame appears; single-stage ignition, only the hot flame appears; two-stage ignition, the hot flame appears after the cool-flame; no-ignition. The temperature of the cool flame in droplet combustion is 650-880 K [2]. Moriue et al. [4] reported that when a $n$-decane droplet is inserted into different ambient temperatures and pressures in normal gravity, all auto-ignition types appear. As shown in Fig. 1 [5], at high pressures where many combustors are in operation, two-stage ignition occurs.

In order to bridge the gap between research on droplet combustion and that on spray combustion, Mikami et al. [6-9] conducted droplet-cloud combustion experiments, "Group Combustion", in the Japanese Experimental Module "Kibo" aboard the International Space Station (ISS), and suggested that a cool flame may appear even in flame spread over droplets [8-9]. Based on this hypothesis, we investigated the appearance of a cool flame in flame spread over $n$-decane droplets, such as three droplets in a straight line, in microgravity 


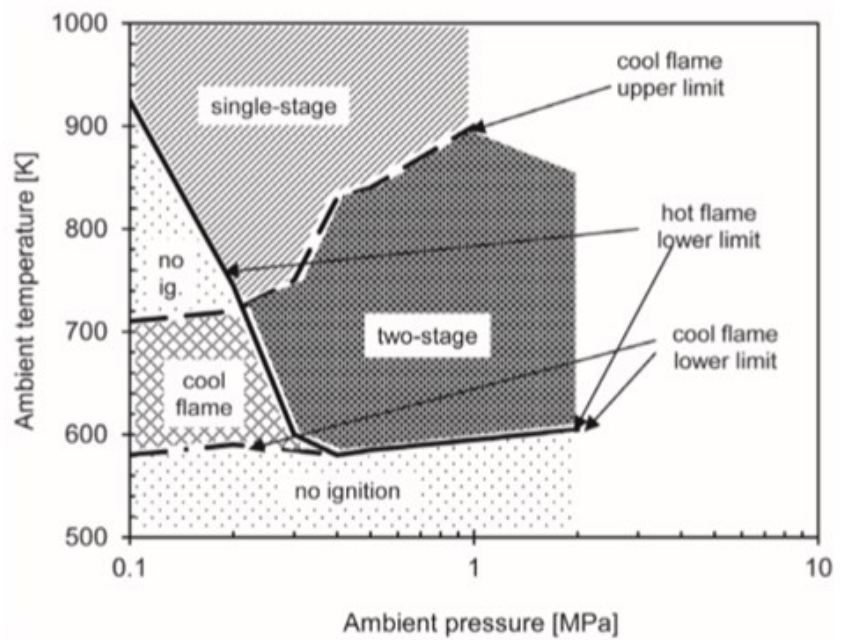

Figure 1. Ignition-mode classification of isolated fuel droplet (fuel: $n$-decane, $d_{0}=0.7 \mathrm{~mm}$, in normal gravity) [5].

[10-11]. We found that the cool flame appears around a droplet heated by interactive burning of two droplets in a narrow range of droplet spacing around the flame-spread limit of two interactive droplets at atmospheric pressure and higher pressures. However, two-stage ignition was not observed [10].

This study focused on the cool flame appearance and two-stage ignition during flame spread over $n$-decane droplets, and further investigated whether two-stage ignition could occur in flame spread over some combinations of $n$-decane droplets at 0.3 and $0.4 \mathrm{MPa}$ in microgravity. Two droplets were heated by burning of droplets to investigate whether two-stage ignition occurs by the interaction of the cool flames. We identified the appearance of a cool flame using an infrared camera and the Thin Filament Pyrometry (TFP) method for SiC fibers tethering the unburned droplet.

\section{Experimental apparatus and procedures}

Figure 2 shows the droplet-array model used in the experiments. Droplets were tethered at the intersection of 14-micron diameter SiC fibers. The droplet spacings between Droplets $B$ and $A$, Droplets $A$ and $L_{1}$, and Droplets $A$ and $L_{2}$ are expressed as $S_{B A} / d_{0}, S_{A L 1} / d_{0}$, and $S_{A L 2} / d_{0}$, respectively, which are normalized by the initial droplet diameter $d_{0}$. Droplets $B$ and $A$ were fixed with $S_{B A} / d_{0}=4$ as interactive droplets. Droplets $L_{1}$ and $L_{2}$ were placed to investigate the cool flame interaction near the flame-spread limit of two interactive droplets, Droplets $B$ and A. The droplet spacing between Droplets $L_{1}$ and $L_{2}$ were fixed with $S_{L_{1 L 2}} / d_{0}=4.1$, which is about the same as the droplet spacing, $S / d_{0}=4$, where the two-stage auto-ignition occurs when two $n$-decane droplets are inserted into high-temperature, high-pressure air [5]. Droplet $B$ was used as the ignition droplet due to the limited microgravity duration.

The experimental apparatus consists of a droplet-array generator, droplet supporting system, and ignition system as shown in Fig. 3. Droplets were generated by moving a fine glass tube to an arbitrary position using a three-axis traverse stage and pushing out a predetermined amount from the micro-syringe with $n$-decane. The initial droplet diameter was $d_{0}=0.5 \mathrm{~mm}$. For the ignition of Droplet $B$, we used the hot wire ignition method in which a half-loop shape $\mathrm{Fe}-\mathrm{Cr}$ wire with a wire diameter of $0.23 \mathrm{~mm}$ is electrically heated. 


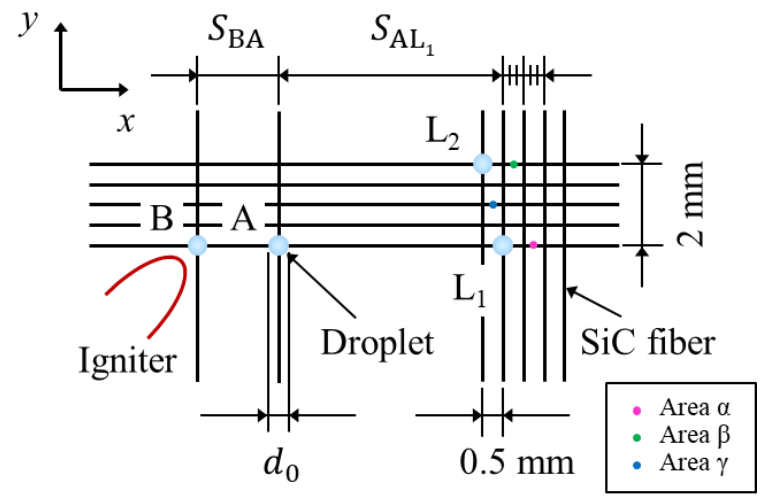

Figure 2. Droplet-array model.

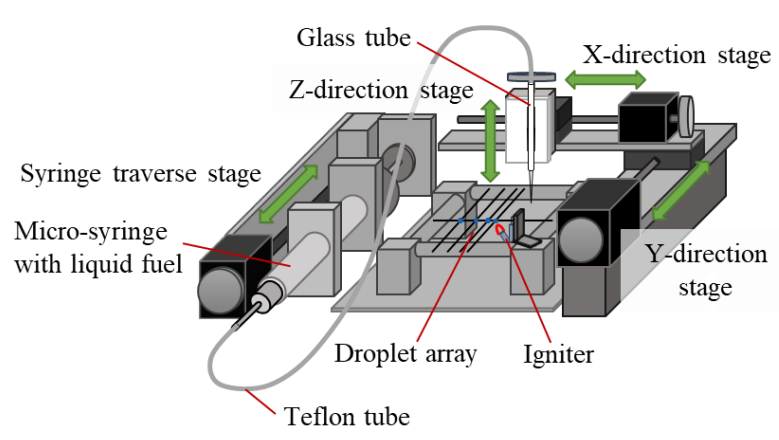

Figure 3. Droplet-array generation system.

The microgravity experiments were conducted at a drop experiment facility of Yamaguchi University. In order to suppress the air drag to the experimental apparatus, we used a drag shield surrounding the apparatus, which drops without contact with the drag shield. The falling distance is $4.5 \mathrm{~m}$ and the microgravity duration is about $0.9 \mathrm{~s}$. Flame spread was observed through a window of the pressure vessel by using an infrared camera (Allied Vision, Goldeye G033 SWIR) with $160 \pm 10 \mathrm{fps}$. The experiments were conducted at room temperature in a pressure vessel pressurized with dry air to the specified pressures of 0.3 and $0.4 \mathrm{MPa}$.

We monitored the temperature changes of the cool flames that appeared around Droplets $L_{1}$ and $L_{2}$ heated by interactive burning of Droplets $B$ and $A$. The temperature around the droplet was measured by the Thin Filament Pyrometry (TFP) method based on the luminosity of $\mathrm{SiC}$ fibers. Therefore, several $\mathrm{SiC}$ fibers were placed around Droplets $\mathrm{L}_{1}$ and $\mathrm{L}_{2}$ to confirm the temperature distribution associated with the cool flame appearance, as shown in Fig. 2. TFP was calibrated using an infrared camera and a SiC fiber in a high-temperature furnace. As shown in Fig. 4, considering the temperature dependence of radiation energy density in Plank's radiation law, we used the fitting function $L=A \exp (-B / T)$, where $T$ is temperature and $A$ and $B$ are constants. The standard deviation of the fitting function and the calibration data is $18.6 \mathrm{~K}$. The calibration range is from $664 \mathrm{~K}$ to $900 \mathrm{~K}$. Due to a large deviation below about $700 \mathrm{~K}$, however, the temperature range measured by the TFP is over $702 \mathrm{~K}$.

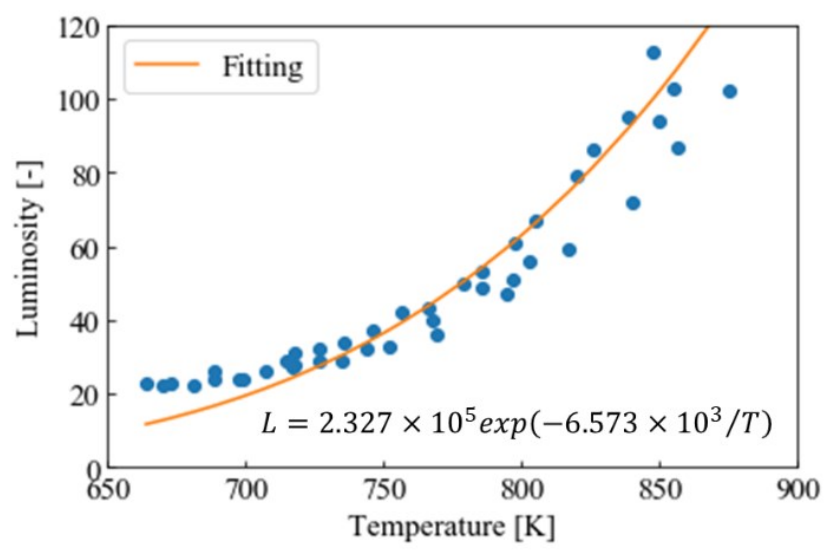

Figure 4. Calibration result of relation between temperature and luminosity of SiC fiber using an infrared camera. 


\section{Results and Discussion}

\section{$0.3 \mathrm{MPa}$ environment (cool-flame ignition occurrence)}

Figure 5 shows the flame spread behavior when Droplets $L_{1}$ and $L_{2}$ are placed at $S_{A L 1} / d_{0}=$ 12, $S_{\mathrm{AL} 2} / d_{0}=11.7$ at $0.3 \mathrm{MPa}$. The starting point of the flame-spread time, $0 \mathrm{~s} / \mathrm{mm}^{2}$, is the moment when the entire Droplet $A$ is enveloped with the flame. The cool flame appeared at $1.88 \mathrm{~s} / \mathrm{mm}^{2}$ from the lower side of Droplet $L_{2}$, which is closer to Droplet $A$, and thereafter expanded gradually to envelope Droplet $L_{2}$ at $2.05 \mathrm{~s} / \mathrm{mm}^{2}$. Following that, the cool flame started to appear from the left side of Droplet $L_{1}$, where the thermal effects of interactive burning of Droplets $B$ and $A$ were relatively large, and enveloped the entire Droplet $L_{1}$ at 2.47 $\mathrm{s} / \mathrm{mm}^{2}$. After that, the cool flame expanded over both droplets. The cool flame, however, did not transit to a hot flame within the microgravity time of this experiment. Droplets $L_{1}$ and $L_{2}$ can be identified as black circles with low-temperature.

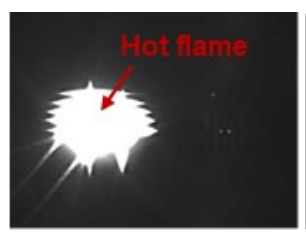

$t / d_{0}^{2}=0 \mathrm{~s} / \mathrm{mm}^{2}$

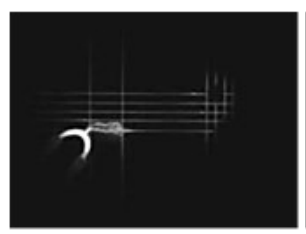

$t / d_{0}^{2}=2.20 \mathrm{~s} / \mathrm{mm}^{2}$

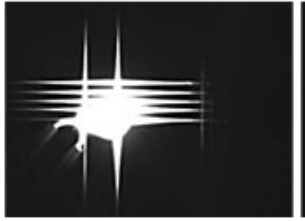

$t / d_{0}^{2}=1.73 \mathrm{~s} / \mathrm{mm}^{2}$

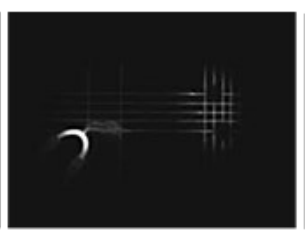

$t / d_{0}^{2}=2.47 \mathrm{~s} / \mathrm{mm}^{2}$

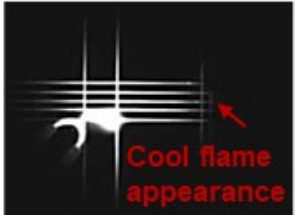

$t / d_{0}^{2}=1.88 \mathrm{~s} / \mathrm{mm}^{2}$

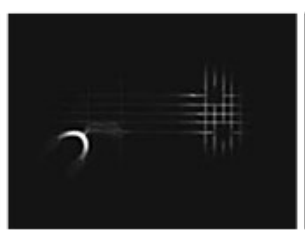

$t / d_{0}^{2}=2.60 \mathrm{~s} / \mathrm{mm}^{2}$

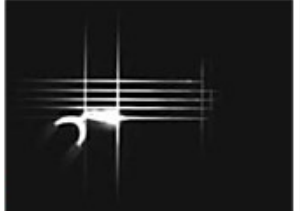

$t / d_{0}^{2}=1.95 \mathrm{~s} / \mathrm{mm}^{2}$

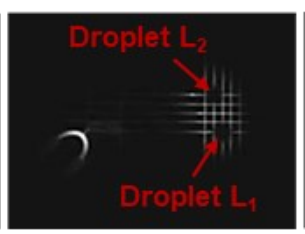

$t / d_{0}^{2}=2.79 \mathrm{~s} / \mathrm{mm}^{2}$

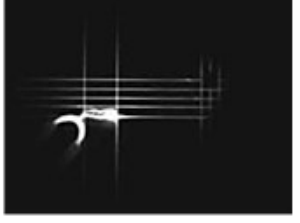

$t / d_{0}^{2}=2.05 \mathrm{~s} / \mathrm{mm}^{2}$

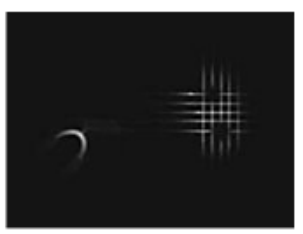

$t / d_{0}^{2}=2.99 \mathrm{~s} / \mathrm{mm}^{2}$

Figure 5. Flame-spread behavior for $S_{\mathrm{AL} 1} / d_{0}=12$ and $S_{\mathrm{AL} 2} / d_{0}=11.7$ at $0.3 \mathrm{MPa}$ (brightness level corrected).

Figure 6 shows the temporal variations of temperature around Droplets $L_{1}$ and $L_{2}$. Area $\alpha$ and $\beta$ are located at $0.75 \mathrm{~mm}$ away from the center of Droplets $L_{1}$ and $L_{2}$ in the $x$-direction, respectively, and Area $\gamma$ is located between Droplets $L_{1}$ and $L_{2}$ as shown in Fig. 2. For reference, we show the temporal variation of temperature in Area $\alpha$ when only Droplet $L_{1}$ is placed at 0.3 MPa [10]. The temperature is calculated using the TFP method from the luminosity of the $\mathrm{SiC}$ fibers. The increase in temperature at an early stage is due to the effect of reflection of infrared light emitting from interactive burning of Droplets $\mathrm{B}$ and $\mathrm{A}$ on the $\mathrm{SiC}$ fibers, which continues up to about $1.7 \mathrm{~s} / \mathrm{mm}^{2}$. The temperature in Area $\gamma$ increases from about $1.9 \mathrm{~s} / \mathrm{mm}^{2}$, indicating that the cool flame appeared from the lower side of Droplet $\mathrm{L}_{2}$. After the entire Droplet $L_{2}$ was enveloped by the cool flame at about $2.0 \mathrm{~s} / \mathrm{mm}^{2}$ and the entire Droplet $\mathrm{L}_{1}$ at about $2.5 \mathrm{~s} / \mathrm{mm}^{2}$, the temperature converged around $800 \mathrm{~K}$. This trend is roughly in agreement with the final temperature when only Droplet $L_{1}$ was placed to investigate the cool flame appearance. On the other hand, the temperature in Area $\gamma$, which is located between Droplets $L_{1}$ and $L_{2}$, continued to increase and reached about $870 \mathrm{~K}$. These results suggest that the temperature rise by the cool flame at each droplet has an upper limit, but the temperature is higher between the two droplets where the heats generated by the cool flames overlap. 


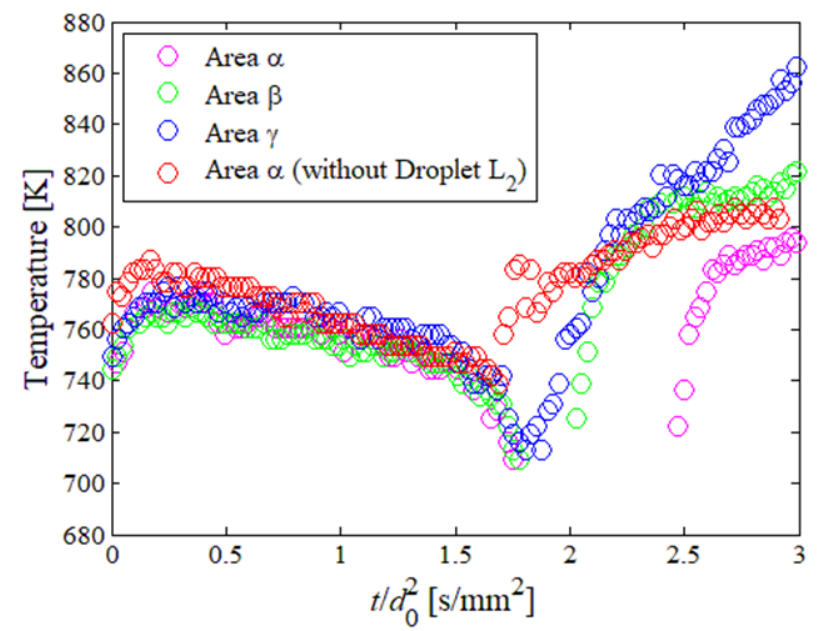

Figure 6. Temporal variations of temperature around Droplets $L_{1}$ and $L_{2}$ at $0.3 \mathrm{MPa}$.

The data without Droplet $L_{2}$ is also shown [10].

\subsection{MPa environment (two-stage ignition occurrence)}

The previous section shows that the temperature between the two droplets increased due to the interaction of the generated heats by the cool flame appearance. One study [11] has reported that the higher the pressure, the more pronounced the appearance of the cool flame. Based on these findings, experiments were conducted to investigate the cool flame appearance by placing two droplets, Droplets $L_{1}$ and $L_{2}$, at a higher ambient pressure of 0.4 MPa as well. Figure 7 shows the flame spread behavior when Droplets $L_{1}$ and $L_{2}$ are placed at $S_{\mathrm{AL} 1} / d_{0}=11$ and $S_{\mathrm{AL} 2} / d_{0}=10.8$ at $0.4 \mathrm{MPa}$. Similar to the result at $0.3 \mathrm{MPa}$ shown in Fig. 5, the cool flame appeared at $2.01 \mathrm{~s} / \mathrm{mm}^{2}$ from the lower side of Droplet $L_{2}$, which is closer to Droplet $A$. Then, the cool flame also appeared around Droplet $L_{1}$ and enveloped the entire two droplets at $2.44 \mathrm{~s} / \mathrm{mm}^{2}$. Thereafter, at the same time as the cool flame expanded around two droplets, and the fiber light emission between the two droplets became stronger until 2.75 $\mathrm{s} / \mathrm{mm}^{2}$, a hot flame appeared at $2.78 \mathrm{~s} / \mathrm{mm}^{2}$ within the microgravity time. This result shows that the cool-flame interaction can cause two-stage ignition in the flame spread over $n$-decane droplets. The two-stage ignition occurrence in this experiment is similar to the findings in the report [5] when two $n$-decane droplets were inserted into high-temperature, high-pressure air, where a cool flame appeared from the side with a strong heat effect, followed by a rapid temperature rise occurrence between the two droplets, leading to the appearance of a hot flame.

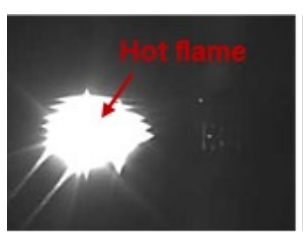

$t / d_{0}^{2}=0 \mathrm{~s} / \mathrm{mm}^{2}$

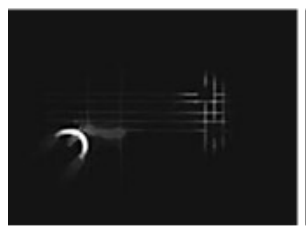

$t / d_{0}^{2}=2.44 \mathrm{~s} / \mathrm{mm}^{2}$

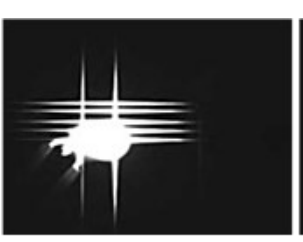

$t / d_{0}^{2}=1.70 \mathrm{~s} / \mathrm{mm}^{2}$

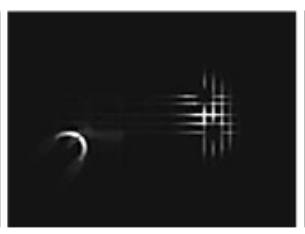

$t / d_{0}^{2}=2.73 \mathrm{~s} / \mathrm{mm}^{2}$

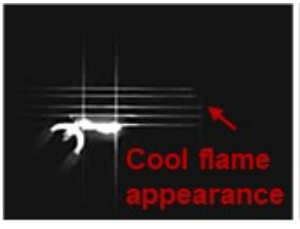

$t / d_{0}^{2}=2.01 \mathrm{~s} / \mathrm{mm}^{2}$

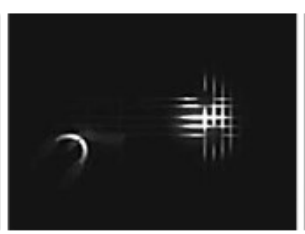

$t / d_{0}^{2}=2.75 \mathrm{~s} / \mathrm{mm}^{2}$

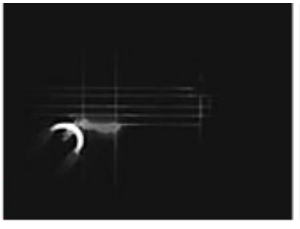

$t / d_{0}^{2}=2.22 \mathrm{~s} / \mathrm{mm}^{2}$

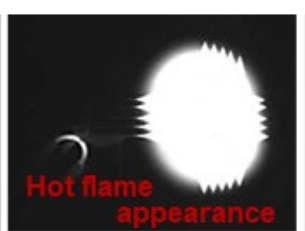

$t / d_{0}^{2}=2.78 \mathrm{~s} / \mathrm{mm}^{2}$

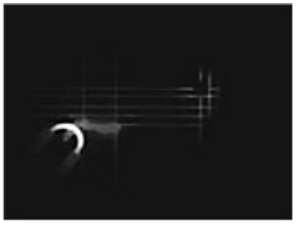

$t / d_{0}^{2}=2.32 \mathrm{~s} / \mathrm{mm}^{2}$

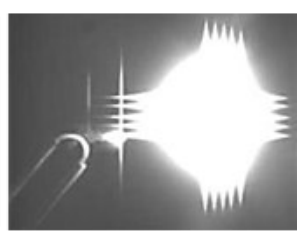

$t / d_{0}^{2}=2.97 \mathrm{~s} / \mathrm{mm}^{2}$

Figure 7. Flame-spread behavior for $S_{\mathrm{AL} 1} / d_{0}=11$ and $S_{\mathrm{AL} 2} / d_{0}=10.8$ at $0.4 \mathrm{MPa}$ (brightness level corrected). 
Figure 8 shows the temporal variations of temperature around Droplets $L_{1}$ and $L_{2}$. The positions of the temperature measurement areas, Areas $\alpha, \beta$, and $\gamma$, are the same as those shown in the previous section. The blue broken line shows the time when the cool flame first appeared, and the red broken line shows the time when the hot flame first occurred. The effect of reflection of infrared light emitting from interactive burning of Droplets $B$ and $A$ continued up to about $1.7 \mathrm{~s} / \mathrm{mm}^{2}$. The temperature in Area $y$ rises from about $2.0 \mathrm{~s} / \mathrm{mm}^{2}$, indicating that the cool flame appeared from the lower side of Droplet $L_{2}$. From the temporal variations of temperature in Areas $\beta$ and $\alpha$, the entire Droplet $L_{2}$ was enveloped with the cool flame at about $2.3 \mathrm{~s} / \mathrm{mm}^{2}$, and then the entire Droplet $L_{1}$ was enveloped at about $2.4 \mathrm{~s} / \mathrm{mm}^{2}$. As opposed to the results at $0.3 \mathrm{MPa}$ shown in Fig. 6 , the temperature rises rapidly in all measurement areas. In particular, the temperature between the two droplets, Area $\gamma$, exceeded the cool flame temperature of $880 \mathrm{~K}$ after about $2.6 \mathrm{~s} / \mathrm{mm}^{2}$, suggesting that the temperature rise caused by the cool flame activated the high-temperature reaction and led to the hot flame.

As for the ignition delay time of the cool and hot flame, the first induction time is defined as the time to the appearance of the cool flame, and the second induction time is defined as the period in which the cool flame activates high-temperature reactions and causes the hot flame [3]. The second induction times are not affected by the initial droplet diameter, however, they do depend on the cool flame temperatures and ambient pressures [3]. As shown in Fig. 8, the second induction time in this experiment was $0.78 \mathrm{~s} / \mathrm{mm}^{2}$, which is about $0.20 \mathrm{~s}$ in time. This induction time is close to the second induction time of $0.19 \mathrm{~s}$ reported in the case of two-stage ignition of two $n$-decane droplets inserted into hot air at $620 \mathrm{~K}$ and an ambient pressure of 0.3 MPa [5]. The reason for the close value of the second induction time in this experiment, even though the ambient pressure was higher than that in the report [5], is that the cool flame in this experiment appeared by supplying heat through the flame spread over droplets at room temperature, and the temperature gradient may have limited the development of the cool flame and prolonged the second induction time.

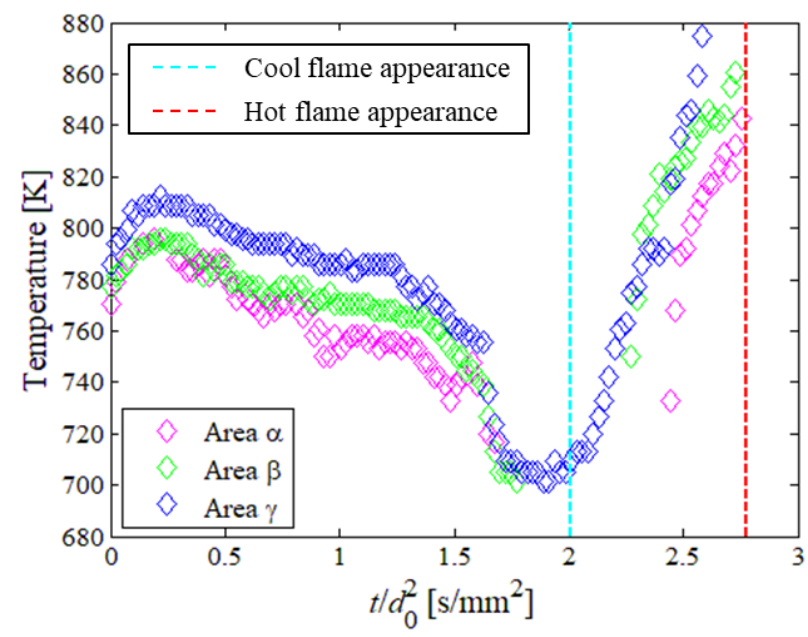

Figure 8. Temporal variations of temperature around Droplets $L_{1}$ and $L_{2}$ at $0.4 \mathrm{MPa}$.

When the position of Droplet $\mathrm{L}_{2}$ was shifted $-0.5 \mathrm{~mm}$ in the y-direction, i.e. $S_{\mathrm{AL} 2} / d_{0}=10.4$, a single-stage ignition took place at $0.4 \mathrm{MPa}$ in which a hot flame occurred without a cool flame appearing. Figure 9 shows the ignition behavior for (a) single-stage ignition and (b) two-stage ignition. Since the droplet spacing between Droplets $L_{1}$ and $L_{2}$ is different, it is not possible to make a general comparison, however, comparing the moments when the hot flame occurred, (a) $2.01 \mathrm{~s} / \mathrm{mm}^{2}$, and (b) $2.78 \mathrm{~s} / \mathrm{mm}^{2}$, the initial flames at the time of two-stage ignition have a 
wider area of light emission. The heat generated by the cool flame probably caused the development of a flammable mixture layer around the two droplets, which led to the larger flame at the moments when the hot flame occurred. Comparison of the flame growth after ignition shows that in Fig. 9(a) the flame continues to expand over time, on the other hand, in Fig. 9(b) the flame diameter reached its maximum after about $0.1 \mathrm{~s} / \mathrm{mm}^{2}$ from the appearance of the hot flame $\left(2.87 \mathrm{~s} / \mathrm{mm}^{2}\right)$ and then began to shrink. The flame began to shrink in a short time because the flammable mixture that had been produced was instantly consumed by the hot flame occurrence.

(a)

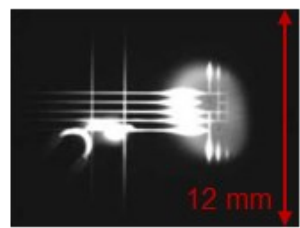

$t / d_{0}^{2}=1.98 \mathrm{~s} / \mathrm{mm}^{2}$

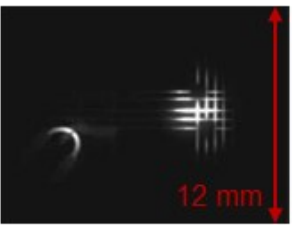

$t / d_{0}^{2}=2.75 \mathrm{~s} / \mathrm{mm}^{2}$

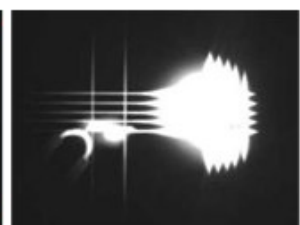

$t / d_{0}^{2}=2.01 \mathrm{~s} / \mathrm{mm}^{2}$

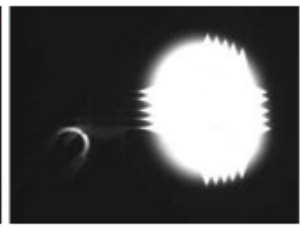

$t / d_{0}^{2}=2.78 \mathrm{~s} / \mathrm{mm}^{2}$



$t / d_{0}^{2}=2.93 \mathrm{~s} / \mathrm{mm}^{2}$

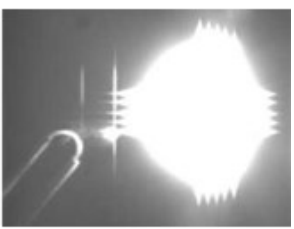

$t / d_{0}^{2}=2.87 \mathrm{~s} / \mathrm{mm}^{2}$

Figure 9. Comparison of ignition behavior at $0.4 \mathrm{MPa}$ : (a) single-stage ignition, (b) two-stage ignition.

In addition, the temporal variation of temperature when only one droplet (Droplet $L_{1}$ ) was placed at $0.4 \mathrm{MPa}$ was also investigated. Figure 10 shows the temporal variations of temperature around Droplet $L_{1}$ in Area $\alpha$. For reference, we show the result of the temporal variation of temperature in Area $\alpha$ when only Droplet $L_{1}$ is placed at $0.3 \mathrm{MPa}$ [10]. The temperature rise due to the cool flame appearance is higher at $0.4 \mathrm{MPa}$ than at $0.3 \mathrm{MPa}$, but a rapid temperature rise was not observed. However, the temperature continues to increase, suggesting the possibility of two-stage ignition with only one droplet when the experiment is conducted in a longer microgravity. On the other hand, we have also reported that the droplet vaporizes completely under the influence of a cool flame when the droplet diameter is smaller, such as $d_{0}=0.4 \mathrm{~mm}[10]$.

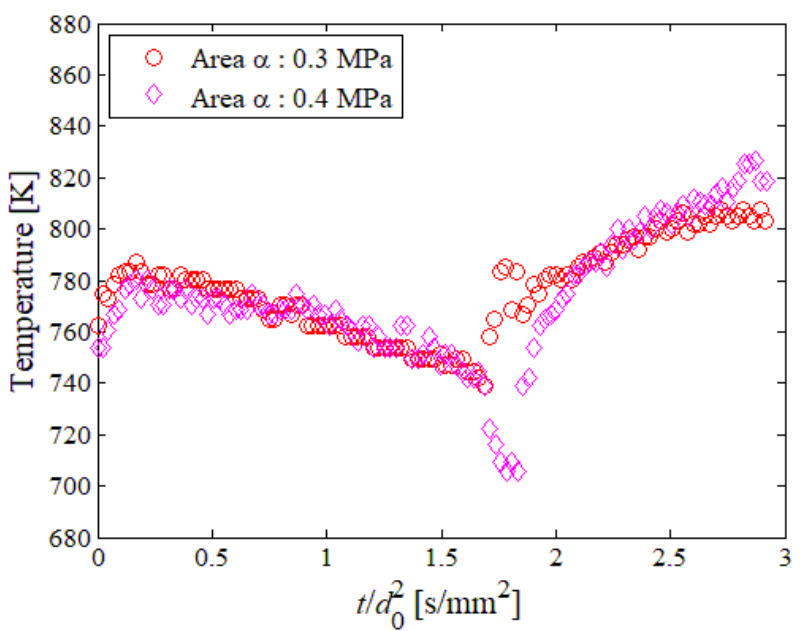

Figure 10. Temporal variations of temperature around Droplets $L_{1}$ and $L_{2}$ at $0.3 \mathrm{MPa}[10]$ and $0.4 \mathrm{MPa}$. 


\section{Conclusions}

This study focused on the cool flame appearance and two-stage ignition during flame spread over $n$-decane droplets in microgravity. Two interactive droplets were placed to investigate whether two-stage ignition could occur around them in flame spread at 0.3 and $0.4 \mathrm{MPa}$. The main conclusions are as follows:

(1) When a cool flame occurs around two interactive droplets, the temperature in the middle region of the two droplets is higher than that on the outside.

(2) After a cool flame appearance, a rapid temperature rise occurs between the two droplets, leading to the appearance of a hot flame at $0.4 \mathrm{MPa}$.

(3) The two-stage ignition of two interactive droplets from the appearance of a cool flame to the occurrence of a hot flame in flame spread over droplets is similar to that of two interactive droplets inserted into high-temperature, high-pressure ambient air.

(4) The initial flame in the case of two-stage ignition is much greater than that in the case of single-stage ignition.

\section{Acknowledgments}

This research was subsidized by JSPS KAKENHI Grant-in-Aid for Scientific Research (B) (18H01625).

\section{References}

[1] Gaydon, A.G. and Moore, N.P.W., 1955, Proc. R. Soc. Lond. A, 233, 184-194.

[2] Farouk, T.I., Dryer, F.L., 2014, Combust. Flame, 161, 565-581.

[3] Tanabe, M., Bolik, T., Eigenbrod, C. and Rath, H.J., Sato, J., Kono, M., 1996, Proc. Combust. Inst, 26, 1637-1643.

[4] Moriue, O., Eigenbrod, C., Rath, H.J., Sato, J., Okai, K., Tsue, M. and Kono, M., 2000, Proc. Combust. Inst., 28, 969-975.

[5] Moriue, O., 2014, Journal of the Combustion Society of Japan (in Japanese), 56, 133-139.

[6] Mikami, M., Nomura, H., Suganuma, Y., Kikuchi, M., Suzuki, T., Nokura, M., 2018, Int. J. Microgravity Sci. Appl., 35 (2), 350202.

[7] Mikami, M., Yoshida, Y., Seo, T., Sakashita, T., Kikuchi, M., Suzuki, T., Nomura, M., 2018, Microgravity Sci. Technol., 30, 535-542.

[8] Matsumoto, K., Yoshida, Y., Mikami, M., Kikuchi, M., Sep. 2.-4. 2019, 29 th $^{\text {European }}$ Conference on Liquid Atomization and Spray Systems.

[9] Mikami, M., Matsumoto, K., Yoshida, Y., Kikuchi, M., Dietrich, D.L., 2021, Proc. Combust. Inst, 38, 3167-3174.

[10] Chikami, Y., Matsumoto, K., Seo, T., Mikami, M., Oct. 23.-26. 2020, 21st Annual Conference on Liquid Atomization and Spray Systems-Asia.

[11] Chikami, Y., Matsumoto, K., Seo, T., Mikami, M., Oct. 4.-7. 2020, JASMAC-32. 